University of Louisville

ThinkIR: The University of Louisville's Institutional Repository

Faculty Scholarship

8-2016

\title{
Sheltering for safety in community women with divorce histories.
}

Ashlee J. Warnecke

University of Louisville

Yvette Z. Sabo

University of Louisville

Vicki E. Burns

Western Governors University

Rafael Fernandez-Botran

University of Louisville

James J. Miller

University of Louisville

See next page for additional authors

Follow this and additional works at: https://ir.library.louisville.edu/faculty

Part of the Domestic and Intimate Partner Violence Commons, and the Psychology Commons

\section{Original Publication Information}

This is the accepted version of the following article:

Warnecke, Ashlee J., et al. "Sheltering for Safety in Community Women with Divorce Histories." 2016.

Violence Against Women, in press.

which can be found in final form at: http://journals.sagepub.com/doi/abs/10.1177/1077801216664426

This Article is brought to you for free and open access by ThinkIR: The University of Louisville's Institutional Repository. It has been accepted for inclusion in Faculty Scholarship by an authorized administrator of ThinkIR: The University of Louisville's Institutional Repository. For more information, please contact thinkir@louisville.edu. 


\section{Authors}

Ashlee J. Warnecke, Yvette Z. Sabo, Vicki E. Burns, Rafael Fernandez-Botran, James J. Miller, and Tamara L. Newton 
In Press in Violence Against Women SHELTERING FOR SAFETY IN COMMUNITY WOMEN WITH DIVORCE HISTORIES

Ashlee J. Warnecke, Department of Psychological and Brain Sciences, University of Louisville, ajwarn01 @louisville.edu; Yvette Z. Szabo, Department of Psychological and Brain Sciences, University of Louisville, yzszab01 @louisville.edu; Vicki E. Burns, School of Nursing, University of Louisville, burnsvicki13@gmail.com; Rafael Fernandez-Botran, Department of Pathology and Laboratory Medicine, University of Louisville, grfern01 @louisville.edu; James J. Miller, Department of Pathology and Laboratory Medicine, University of Louisville; Tamara L. Newton, Department of Psychological and Brain Sciences, University of Louisville, tlnewton@louisville.edu

Vicki E. Burns is now at Western Governors University.

Correspondence concerning this article should be addressed to Tamara L. Newton, Department of Psychological and Brain Sciences, University of Louisville, Louisville, KY 40292, (502) 8520070 (phone), (502) 852-8904 (fax), tlnewton@ louisville.edu

\section{AUTHOR NOTE}

We published additional manuscripts that consider this sample (Fleming, Newton, FernandezBotran, Miller, \& Burns, 2012; Newton, Burns, Miller, \& Fernandez-Botran, 2015) or the subsample with biological measures (Fernandez-Botran, Miller, Burns, \& Newton, 2011; Newton et al., 2013; Newton, Fernandez-Botran, Miller, \& Burns, 2014). This manuscript is dedicated to the memory of our colleague Dr. James J. Miller. His support and expertise will be sorely missed.

\section{FUNDING}

This research was funded by the National Institute on Aging.

KEY WORDS: coercive control, divorce, intimate partner abuse, shelter 


\begin{abstract}
This cross-sectional study compared the prevalence of formal and informal sheltering (i.e., staying in an agency shelter, or with friends/family, respectively), and evaluated associations with abuse severity. Community women $(N=197)$ with divorce histories reported on lifetime intimate partner abuse, including sheltering for safety. Prevalence of informal sheltering (43\%) exceeded that of formal sheltering (11\%). Rates/levels of coercive control, severe violence, injury, and police involvement were comparable for women who sheltered formally or informally, and exceeded those of women who never sheltered. Sheltering histories can be identified in community samples of women with divorce histories. Informal sheltering is prevalent, and comparable to formal sheltering in terms of correlations with abuse severity.
\end{abstract}


Intimate partner abuse is heterogeneous, and addressing this in research will be critical to advance understanding of the causes and consequences of abuse (Kelly \& Johnson, 2008). Variations in sampling, or the different ways participants are selected for research, have been key to identifying abuse heterogeneity (Johnson, 1995). For example, relatively distinct constellations of abuse can be differentiated by the presence or absence of severe, injurious physical violence and coercive control (i.e., intimidation, surveillance, isolation from friends and family, and other limits on freedom). Both victimization experiences are more likely to be identified in women recruited from shelters, or other agencies such as courts, than in women recruited from the community (Johnson, 2006). Presumably, however, women with histories of seeking shelter can be identified in community samples. If so, then this calls into question whether it is necessary to recruit research volunteers from both shelters and the community for a broad representation of abuse experiences, or whether heterogeneity can be revealed in community samples alone.

The present study drew on an existing sample of community women with divorce histories to further understanding of sheltering and abuse heterogeneity. The purpose of the study was three-fold. The first aim was to determine the prevalence of formal sheltering (i.e., having sought safety in an agency, or community, shelter). The second aim was to determine the prevalence of informal sheltering (i.e., having sought safety by staying with friends or family), a less well-studied type of sheltering. The third aim was to examine associations between sheltering history (none, informal, formal) and abuse severity indicators that have been traditionally linked to samples of women recruited directly from shelters. Overall, this study aimed to determine whether abuse heterogeneity can be identified, and meaningfully linked to sheltering histories, in a community sample. 
Some research suggests that it might be difficult to identify women with formal sheltering histories in community samples. For example, cases of "clinical" abuse (i.e., abuse more traditionally associated with shelter samples) were identified in one epidemiological community sample, and sheltering history was assessed (Ehrensaft, Moffitt, \& Caspi, 2004). A history of formal sheltering was reported by only 1 woman of the 38 who were classified with clinical abuse. However, because sheltering is one resource people may use as they exit a relationship, the prevalence of formal sheltering may depend on whether persons with histories of separation or divorce are included in the sample. Supporting this idea, in two studies of community persons reporting intimate partner abuse by a current or former partner, $11 \%$ of women reported ever contacting shelters in the previous five years (Ansara \& Hindin, 2010; Barrett \& St Pierre, 2011). In a community sample of women separated from abusive partners for about 1.5 years, $1.6 \%$ of women had utilized a domestic violence shelter in the past month (Ford-Gilboe et al., 2015). In a small subsample of rural women from the same study, $44 \%$ reported ever using shelters (Riddell, Ford-Gilboe, \& Leipert, 2009). Thus, histories of formal sheltering can be identified in women from community samples, and rates are higher among samples that include, or are selected for, persons who have left abusive relationships.

In contrast to use of agency shelters, considered a formal resource, sheltering with friends and family is an informal resource (Goodman, Dutton, Vankos, \& Weinfurt, 2005). Generally speaking, informal resource use is more common than formal resource use among women with abuse histories, but studies that have compared rates of each typically have not considered formal and informal sheltering (Ansara \& Hindin, 2010; Barrett \& St Pierre, 2011; Coker, Derrick, Lumpkin, Aldrich, \& Oldendick, 2000; Pakieser, Lenaghan, \& Muelleman, 1998). In one study that did, $70 \%$ of community women who had left abusive partners reported sheltering 
with friends/family, a rate 50\% higher than that reported for formal sheltering (Riddell et al., 2009). Similarly, in a large sample of women with abuse histories, women who left their relationships stayed with informal networks (friends, family) at rates 4 to 10 times higher than they stayed in formal shelters (Fanslow \& Robinson, 2010). Thus, informal sheltering may be more common than formal sheltering.

Given that women with sheltering histories, including histories of formal sheltering, can be identified in community samples, abuse heterogeneity may also be identifiable in community samples. In support of this, past research has found that intimate partner abuse traditionally associated with shelter samples (i.e., abuse characterized by the presence of coercive control and severe, injurious violence) can be identified in women recruited from the community, but the prevalence is low (Ansara \& Hindin, 2010; Ehrensaft, Moffitt, \& Caspi, 2006; Johnson, 2006). However, in community samples of separated or divorced persons, the rates of severe, controlling abuse are 25 to 50 times higher than in community persons who are currently partnered (Ansara \& Hindin, 2010). Indeed, assessing former, rather than current, intimate relationships is more likely to identify severe, controlling abuse in community samples (Johnson, Leone, \& Xu, 2014).

Past research provides evidence that both sheltering histories and abuse heterogeneity can be identified in community samples, particularly when considering former intimate relationships. Two final questions concern whether sheltering in community samples relates to abuse heterogeneity in predictable ways (i.e., in a manner similar to that observed for women recruited directly from shelters), and whether this is consistent across both formal and informal sheltering. The broader literature on formal and informal resource use and intimate partner abuse severity may inform these questions. The positive correlation between use of formal resources and 
controlling, injurious abuse is well-documented, even in community samples (Ansara \& Hindin, 2010; Johnson, 1995). In contrast, there is some inconsistency in associations between use of informal resources and abuse severity. Some studies show that informal resources are used widely by women across differing levels of abuse severity, and are only somewhat more likely to be used by persons reporting severe, controlling abuse (Ansara \& Hindin, 2010). Other studies show that informal resources are equally likely, or sometimes less likely, to be used by persons with more severe abuse (Leone, Johnson, \& Cohan, 2007). However, these studies did not specifically consider informal sheltering. In one study that did, formal sheltering was more common among women with severe, controlling abuse versus less severe abuse; the opposite was found for informal sheltering. However, even among women with histories of severe abuse, rates of informal sheltering exceeded rates of formal sheltering (Johnson \& Leone, 2005). Thus, informal sheltering is a commonly used resource, even among women reporting severe, controlling intimate partner abuse.

In sum, the present study examined whether women with sheltering histories can be identified in a community sample, whether rates of formal and informal sheltering differ, and whether intimate partner abuse heterogeneity is associated with sheltering history in a predictable manner. Because all women had histories of divorce or separation, we expected to identify women with histories of formal sheltering. However, we predicted that histories of informal sheltering would be more prevalent. Further, we predicted that sheltering history (none, informal, formal) would be associated with the following indicators of abuse severity: frequency of coercive control, exposure to severe violence (both physical and sexual), injury-including general physical injury (Forjuoh, Coben, \& Gondolf, 1998) and head injury (Corrigan, Wolfe, Mysiw, Jackson, \& Bogner, 2003; Monahan \& O'Leary, 1999)—and ever obtaining an 
emergency protective order (EPO)/police involvement. We expected women with histories of formal sheltering to report rates or levels of abuse severity exceeding those reported by women with histories of informal sheltering. Women in the latter group, in turn, were expected to report more severe abuse than women without histories of sheltering.

\section{METHOD}

\section{$\underline{\text { Participant Recruitment and Selection }}$}

As part of a broader investigation of intimate partner violence history and aging, physically healthy, midlife women with histories of separation or divorce from a stressful relationship were recruited from the community (Newton et al., 2011). Eligibility criteria, established by telephone interview, included English language proficiency; history of separation or divorce from a cohabiting male partner; no experience of intimate partner abuse in the past year and, if re-partnered, no history of intimate partner abuse in the current relationship; no ongoing divorce-related stress; and no psychiatric hospitalization in the past year. Eligible women participated in either a laboratory phase that included collection of biological samples, or a questionnaire-only phase, and were compensated either $\$ 140.00$ or $\$ 60.00$, respectively. The present study combined questionnaire data from both phases. Of 577 callers, 118 were ineligible, and 246 chose not to participate or were lost to contact. Of the 213 women who were enrolled, 197 with complete data for the sheltering questions are included in the present study. $\underline{\text { Measures }}$

\section{Sociodemographics}

Women reported their age, ethnicity, annual household income, educational attainment, number of times they had ever divorced or separated from a cohabiting intimate partner, and years since their last divorce/separation. 


\section{Sheltering History}

For up to four intimate relationships from which they had divorced or separated, women indicated if they had ever left to seek safe shelter in the community, with friends/family, or both. Woman who reported never seeking safe shelter in any past intimate relationship, either with friends/family or in the community, were classified as "never." Women who reported sheltering in the community in one or more prior intimate relationship were classified as "formal." (Some women in this group may have also used informal sheltering.) Women who reported sheltering only with friends or family in one or more prior intimate relationship were classified as "informal."

\section{Coercive Control}

The 7-item dominance/isolation subscale of the Psychological Maltreatment of Women Inventory-Short Form (Tolman, 1999) measured coercive control. Women rated the frequency of each item $(1=$ never, $5=$ very frequently $)$ with respect to their past intimate relationships, collectively. Ratings were summed to form a total score (Cronbach's $\alpha=.84$ ). In a community sample of divorcing mothers, the construct validity of this measure was established by showing expected relations with violence severity, fear, and perceived threat in the intimate relationship (Hardesty et al., 2015). Additionally, a score $\geq 19$ was suggested for identifying high levels of coercive control. Therefore, we also computed a dichotomous score to indicate high ( $\geq 19)$ versus low $(<19)$ levels of coercive control.

\section{Severe Violence and General Injury}

The 7-item severe physical assault subscale, the 4-item severe sexual coercion subscale, and the 6-item injury subscale of the Revised Conflict Tactics Scale (Straus, Hamby, BoneyMcCoy, \& Sugarman, 1996) measured severe violence exposure and general injury. For each 
item, women rated the frequency of occurrence $(0=$ never, $1=$ once, $2=$ twice, $3=3-5$ times, 4 =6-10 times, $5=11-20$ times, $6=$ more than 20 times $)$ with respect to their past intimate relationships collectively. Variety scoring was used (Moffitt et al., 1997). Severe violence exposure was measured by counting the number of severe physical assault and severe sexual coercion items rated $\geq 1$, for a total score ranging from 0 to 11 (Cronbach's $\alpha=.86$ ). General injury was measured by counting the number of injury items rated $\geq 1$. The item assessing head injury was dropped to reduce overlap with the head injury assessment. Thus, the total score ranged from 0 to 5 (Cronbach's $\alpha=.80$ ).

\section{Head Injury}

Women were asked if they had ever suffered a blow to their head as an adult due to accident or abuse. For the 93 women who responded "yes," a follow-up question determined if women had received a blow to their head due specifically to violence or abuse by their intimate partner. Responses (never, once, twice, and three or more times) were recoded to yes or no. As not all women received this question, the sample size is smaller than in other analyses. Women who responded affirmatively were assessed for a history of concussive symptoms; they reported the number of times such a blow to the head caused symptoms of concussion (e.g., headache, nausea, dizziness, fatigue, drowsiness, being in a "fog," difficulty concentrating, feeling slowed down) or loss of consciousness (Guskiewicz et al., 2005). A history of concussive symptoms was coded as absent (a response of "zero" to both questions) or present.

\section{EPO/Police Involvement}

For up to four relationships from which they had divorced or separated, women reported (yes or no) whether they ever contacted the police or filed an EPO to stay safe.

\section{Data Analytic Strategy}


Distributions for continuous variables (coercive control, severe violence exposure, and general injury) were significantly skewed or did not meet the assumption of normality. Therefore, Kruskal-Wallis tests, a non-parametric alternative to analysis of variance that utilizes a chi-square approximation, were used for data analysis. When the omnibus test was significant, follow-up tests were conducted to determine which groups differed. Effect size $(r)$ is reported for follow-up analyses, where $r=\mathrm{z} /$ square root of $N$ (Field, 2013).

For categorical variables (coercive control dichotomous score, head injury, concussion, and EPO/police involvement), analyses were conducted with chi-square tests, or Fisher's exact test when cell-size assumption was not met. When the omnibus chi-square was significant, follow-up chi-square tests were used to determine which groups differed. Effect size $(\varphi)$ is reported for omnibus tests, as well as follow-up analyses.

Alpha for all omnibus tests was set to .05. For follow-up comparisons between sheltering history groups, a Bonferroni correction was applied (.05/3), resulting in an alpha of .016.

\section{RESULTS}

\section{$\underline{\text { Participant Characteristics }}$}

As shown in Table 1, women were in their fifties, and most self-identified as White/Caucasian, reported an annual income of less than $\$ 60,000.00$, and had completed at least some college coursework. Most women had been divorced or separated fewer than three times, and the median number of years since the end of the last relationship was 9 .

The median level of coercive control was just below 19, the cut-off score indicating high levels. The median level of severe violence was 2, and the median level of general injury was 2 . About two-thirds of women who answered the head injury question were positive for a history of head injury due to intimate partner abuse (this represents $31 \%$ of the overall sample). Over twothirds of women with such a head injury history reported an associated history of concussive 
symptoms. In the overall sample, just under $50 \%$ of women reported EPO obtainment/police involvement.

Table 1 about here

Histories of Sheltering for Safety

Of the 197 women in the overall sample, $46 \%(n=91)$ never sheltered for safety, $43 \%(n$ $=84)$ sheltered informally with friends or family, and $11 \%(n=22)$ sheltered formally. Thirteen women who sheltered formally also reported histories of informal sheltering.

Sheltering History and Abuse Severity

\section{Coercive Control}

There was a statistically significant association between sheltering history and exposure to coercive control, $\chi^{2}(2, N=197)=31.899, p<.0001$ (see Figure $\left.1 \mathrm{~A}\right)$. Women who sheltered formally or informally did not differ in exposure to coercive control $(p=.30, r(106)=.10)$, but both groups were exposed to more coercive control than were women who had never sheltered $(p s<.0001, r(113)=.37$ for formal sheltering, and $r(175)=.38$ for informal sheltering, respectively). There was also a statistically significant association between sheltering history and the dichotomous coercive control score, $\chi^{2}(2, N=197)=17.21, p<.0002, \varphi=.30$. Compared to women who never sheltered, those who sheltered formally or informally were more likely to report high levels of coercive control ( $p \mathrm{~s}<.003, \varphi=.28$, and $\varphi=.28$, respectively); there were no statistically significant differences between the latter groups $(p=.52, \varphi=.06)$.

Severe Violence Exposure 
There was a statistically significant association between sheltering history and severe violence exposure, $\chi^{2}(2, N=196)=60.69, p<.0001$ (see Figure 1B). Women who sheltered formally reported more severe violence exposure than did those who sheltered informally, but this difference did not meet the Bonferroni-adjusted $p$-value for statistical significance $(p=.04, r$ $(106)=.20)$. Both groups, however, experienced more severe violence exposure than women who had never sheltered $(p s<.0001, r(112)=.53$, and $r(174)=.52$, respectively).

Figure 1 about here

\section{Injury}

There was a statistically significant association between sheltering history and general injury, $\chi^{2}(2, N=197)=49.98, p<.0001$ (see Figure $\left.1 C\right)$. Women who sheltered formally or informally did not differ in levels of general injury $(p=.11, r(106)=.16)$, but both groups experienced more general injury than women who had never sheltered $(p s<.0001, r(113)=.52$, and $r(175)=.46$, respectively).

There was also a statistically significant relationship between sheltering history and head injury due to abuse or violence from a partner, Fisher's exact test $p<.0001, \varphi=.52$ (see Figure 2A). Women who sheltered formally or informally did not differ in terms of reported head injury $(p=.18, \varphi=.17)$. Both groups were more likely to report a head injury due to intimate partner abuse than were those who never sheltered ( $p$ s $<.0001, \varphi=.62$, and $\varphi=.48$, respectively). The relationship between sheltering history and post-concussive symptoms was not statistically significant, Fisher's exact test $p=.35$. Thus, as shown in Figure 2B, abuse-related head injury was likely to lead to concussive symptoms, regardless of sheltering history. 
Figure 2 about here

\section{EPO/Police Involvement}

There was a statistically significant relationship between sheltering history and obtaining an $\mathrm{EPO} /$ police involvement $\chi^{2}(2, N=196)=57.82, p<.0001, \varphi=.54$ (see Figure $\left.2 \mathrm{C}\right)$. Women who sheltered formally or informally did not differ in terms of reported EPO/police involvement $(p=.45, \varphi=.07)$. Both groups were more likely to report a history of EPO/police involvement than were those who never sheltered $(p s<.001, \varphi=.53$, and $\varphi=.53$, respectively). $\underline{\text { Informal Sheltering and Formal Resource Use }}$

As expected, abuse severity among women who sheltered formally or informally exceeded that of women who had never sheltered. Unexpectedly, women who sheltered formally or informally showed comparable abuse severity. This unexpected pattern might reflect the fact that informal sheltering, like formal sheltering, was associated with reporting a history of EPO/police involvement, a formal resource. Prior research shows that formal resource use, compared with informal resource use, is associated with more severe abuse (Ansara \& Hindin, 2010).

To examine this idea, women were re-classified as follows: Any formal resource use (i.e., community sheltering or police/EPO involvement, $n=95$ ); informal sheltering/no formal resource use $(n=26)$; no sheltering/no formal resource use $(n=75)$. (One woman with no sheltering history and missing data for police/EPO involvement could not be re-classified, and therefore $N=196$.) Using this re-classification, group differences in coercive control (overall 
exposure, and dichotomous scores), severe violence exposure, and both types of injury were tested.

There were statistically significant associations between the re-classification and all abuse severity indicators $(p s \leq .0002)$. Women reporting no sheltering/no formal resource use differed from women in the other two groups; they reported lower levels of coercive control exposure, severe violence exposure, and general injury, and were less likely to report a history of abuse-related head injury $(p s<.01)$. They were also less likely to be characterized by high levels of coercive control compared to women reporting formal resource use $(p<.001)$, but not compared to women reporting informal sheltering/no formal resource use $(p=.08)$.

In terms of comparisons between women reporting formal resource use versus informal sheltering/no formal resource use, there were no statistically significant differences for coercive control (overall exposure, or high levels; $p s=.16$ and .26 , respectively) or severe violence exposure $(p=.11)$. However, women who used formal resources reported more general injury, and were more likely to report a history of abuse-related head injury $(p s \leq .01)$. Thus, for injury - but not for coercive control or severe violence - the unexpected equivalence of women reporting formal versus informal sheltering reflects the fact that both types of sheltering were associated with other formal resource use.

\section{DISCUSSION}

The aims of this study were to determine whether women with histories of formal, agency sheltering could be identified in a community sample, and whether the prevalence of informal sheltering exceeded that of formal sheltering. Additionally, this study aimed to determine whether sheltering history in a community sample is associated with abuse severity indicators that have been traditionally linked with samples recruited directly from shelters. 
Regarding the first aim, histories of formal, agency sheltering were identified in this sample of community women recruited for having divorced or separated from a stressful intimate relationship. This is consistent with previous research in which women with histories of formal sheltering were identified in community samples that included persons reporting on abuse in former relationships. The prevalence rate in the present study-11\%-is comparable to that reported by some studies (Ansara \& Hindin, 2010; Barrett \& St Pierre, 2011), but lower than that reported by others (Riddell et al., 2009). These differences might be explained by variations in the range of abuse severity in a given sample. Although further research will be necessary to generate more stable estimates of the prevalence rates of formal sheltering in community samples and identify factors that influence these rates, the present study adds support to previous research indicating that identification of formal sheltering in a community sample is possible.

Regarding aim two, the rate of informal sheltering was approximately four times higher than that of formal sheltering. Thus, while women with histories of agency sheltering can be identified in community samples, more women report histories of informally sheltering for safety. Past research has identified informal resources as being more commonly used than formal resources to cope with, survive, and/or escape an abusive relationship. Therefore, the observation that informal sheltering, one type of informal resource, is more prevalent within a community sample is consistent with the broader literature on intimate partner abuse and resource use (Ansara \& Hindin, 2010).

The third aim was to determine whether, in a community sample, different sheltering histories are associated with abuse severity indicators, especially indicators of severe, controlling abuse commonly identified in women recruited directly from shelters. This is particularly important as the ability to identify abuse heterogeneity in a community sample could have 
implications for recruitment of research participants, and efforts to increase understanding of the causes and consequences of abuse. Coercive control, severe violence exposure, injury, and $\mathrm{EPO} /$ police involvement were all greater or more common among women with any sheltering history compared to those with no sheltering history. Further, these severity indictors were comparable among women who sheltered formally or informally.

The pattern of results wherein those who sheltered formally or informally did not differ was contrary to our hypotheses. Additional analyses showed that, for injury, this pattern reflected the fact that informal sheltering, like formal sheltering, clustered with EPO/police involvement; the latter is a formal resource, and formal resource use is associated with more severe abuse (Ansara \& Hindin, 2010). Thus, in community samples of divorced/separated persons, women with histories of formal sheltering can be identified, and they are characterized by abuse histories that bear similarities to women recruited from shelters. Furthermore, women with informal sheltering histories have similarly severe injury histories when there is also evidence of EPO/police involvement, and our data show that this occurred in $70 \%$ of the cases. Thus, informal sheltering is a correlate of abuse severity in community women, identifying experiences that are similar to those of community women who have sheltered formally.

There may be similarities between formal and informal sheltering that explain why both groups clustered with other formal resource use, and did not differ substantially in terms of abuse severity. For example, opportunities for safety and social support are likely present in both formal and informal sheltering. Although these factors were not considered here, they may be important correlates to examine in future research. Furthermore, demographics and resources present before seeking shelter could have a role in whether or not women seek shelter and what type of shelter they seek. For example, some research shows that women who do not use formal 
shelters have a higher income than those who do (Grossman \& Lundy, 2007; Waldrop \& Resick, 2004). Additionally, there are cultural differences in help-seeking. It has been reported that ethnic minority women are more likely to utilize informal rather than formal resources, at least when initially seeking help (Bent-Goodley, 2007). However, other studies showed that ethnic minority women were less likely than non-Hispanic White women to seek help from their friends, but more likely to seek help from the police, after controlling for abuse severity (Flicker et al., 2011). These apparent inconsistencies might partially reflect the operation of unmeasured culture-related factors (e.g., acculturation, immigrant status, and experiences with cultural insensitivity or discrimination within institutions) that influence help-seeking and that vary across study samples (Bent-Goodley, 2007; Flicker et al., 2011; Reina, Lohman, \& Maldonado, 2014). Although the sample demographics in the current study did not allow for comparisons based on ethnicity, and this was not an aim of this paper, examination of this could be important in future work. That is, although women who shelter formally versus informally do not differ in terms of abuse severity, they may differ in other domains. Combining the perspective that formal and informal sheltering offer similar resources with the importance of cultural and demographic factors could be relevant in future work, as it is possible that women are seeking the same resource through different means based on demographic and cultural characteristics and experiences.

When considering abuse severity indicators, results for coercive control deserve particular attention. Coercive control has played a key role in helping to identify qualitatively different types of abuse. In studies that contrast agency and community samples, it is pivotal for identifying the abuse type that has been associated with agency samples_-intimate terrorism or coercive controlling violence (Johnson, 2006). In this respect, results from the present study 
provide several interesting observations. First, even in this community sample, women with histories of agency sheltering showed high levels of coercive control. This finding confirms and extends a pattern observed in the literature, and shows that this important dimension of abuse can be identified in a community sample of women reporting about former relationships. Second, it is notable that exposure to coercive control, and rates of high coercive control, were comparable in women who sheltered formally or informally, especially because coercive control has been key to identifying agency-level abuse. Even after disentangling EPO/police involvement, women who sheltered formally or informally were comparable on levels of coercive control exposure. Overall, this suggests that "sheltering for safety" — whether formally or informallymay be an overarching experience that helps identify women who have been exposed to coercive control and associated limits on freedom, though additional research will be necessary to confirm this idea.

Results for head injury and concussive symptoms also deserve comment. Despite differences in rates of head injury among those with versus without sheltering histories, reported concussive symptoms did not differ. That is, most women who reported a head injury due to abuse also reported concussive symptoms, regardless of sheltering history. Future research should further examine abuse-related head injuries and concussive symptoms, as this could have implications for understanding abuse severity, as well as for addressing medical and mental health outcomes of women with a history of abuse.

Though the present study contributes broadly to the research on sheltering for safety in women with divorce histories, it has several limitations that should be noted. First, assessments were made globally across all relationships from which women had divorced or separated. Therefore, for reports of violence and coercive control, women could be extrapolating from 
different relationships. This raises questions about whether women experienced coercive control or severe violence in a single relationship. Second, the study relied on retrospective reporting, and most women had been out of their relationships for many years; thus, accuracy of reports may be limited by the fallibility of memory. However, as discussed previously, some research shows that identifying severe abuse in community samples is more likely when considering former relationships (Johnson et al., 2014). That is, it is emerging that this is an important group of women to study. Future research should evaluate the reliability of reports of basic characteristics of abuse experiences (e.g., sheltering, police involvement/EPO) to help inform the field. Third, our results underscore the importance of formal resource use in abuse severity, and it is therefore important to recognize that we did not comprehensively assess formal resource use (e.g., medical professionals, mental health professionals, and clergy). Thus, it is always possible that elevations in abuse severity indicators observed for women with histories of sheltering informally (but without a history of EPO/police involvement) could be attributed to unmeasured formal resource use in this group. Fourth, although one of our aims was to determine whether abuse experiences that characterize women recruited from agency shelters can be identified in community samples, we made no direct comparisons with an agency shelter sample. Research that recruits both community and shelter samples will be necessary to extend this comparison.

In conclusion, women with sheltering histories can be identified in community samples recruited for histories of divorce of separation. Abuse heterogeneity can also be identified in such samples. Studies that directly compare persons recruited from the community or from shelters, and that gather reports about a single prior relationship, will be helpful to further characterize this heterogeneity. This information will assist intimate partner abuse researchers in making important decisions about sampling. The present study also revealed that informal 
sheltering, a type of sheltering not typically considered, is associated with severity indicators similar to those of formal sheltering. Future research, therefore, should consider not only whether or not persons shelter, but also where they shelter. Factors that lead to choosing one type of sheltering over another should also be examined. This could have implications for public policy, as those who work with individuals leaving abusive relationships gain information on what types of sheltering persons use and why. For example, if future research supports informal sheltering as a commonly used resource associated with severity indicators similar to those known to characterize formal sheltering, then programs that reach out to those sheltering informally could be useful. 


\section{REFERENCES}

Ansara, D. L., \& Hindin, M. J. (2010). Exploring gender differences in the patterns of intimate partner violence in Canada: A latent class approach. Journal of Epidemiology and Community Health, 64, 849-854. doi: 10.1136/jech.2009.095208

Barrett, B. J., \& St Pierre, M. (2011). Variations in women's help seeking in response to intimate partner violence: Findings from a Canadian population-based study. Violence Against Women, 17, 47-70. doi: 10.1177/1077801210394273

Bent-Goodley, T. B. (2007). Health disparities and violence against women: Why and how cultural and societal influences matter. Trauma, Violence, \& Abuse, 8, 90-104. doi: $10.1177 / 1524838007301160$

Coker, A. L., Derrick, C., Lumpkin, J. L., Aldrich, T. E., \& Oldendick, R. (2000). Help-seeking for intimate partner violence and forced sex in South Carolina. American Journal of Preventive Medicine, 19(4), 316-320.

Corrigan, J. D., Wolfe, M., Mysiw, W. J., Jackson, R. D., \& Bogner, J. A. (2003). Early identification of mild traumatic brain injury in female victims of domestic violence. American Journal of Obstetrics and Gynecology, 188, S71-S76. doi: 10.1067/mob.2003.404

Ehrensaft, M. K., Moffitt, T. E., \& Caspi, A. (2004). Clinically abusive relationships in an unselected birth cohort: Men's and women's participation and developmental antecedents. Journal of Abnormal Psychology, 113, 258-270. doi: 10.1037/0021-843x.113.2.258

Ehrensaft, M. K., Moffitt, T. E., \& Caspi, A. (2006). Is domestic violence followed by an increased risk of psychiatric disorders among women but not among men? A longitudinal 
cohort study. American Journal of Psychiatry, 163, 885-892. doi:

10.1176/appi.ajp.163.5.885

Fanslow, J. L., \& Robinson, E. M. (2010). Help-seeking behaviors and reasons for help seeking reported by a representative sample of women victims of intimate partner violence in New Zealand. Journal of Interpersonal Violence, 25, 929-951. doi: $10.1177 / 0886260509336963$

Fernandez-Botran, R., Miller, J. J., Burns, V. E., \& Newton, T. L. (2011). Correlations among inflammatory markers in plasma, saliva and oral mucosal transudate in post-menopausal women with past intimate partner violence. Brain, Behavior, and Immunity, 25, 314-321. doi: $10.1016 /$ j.bbi.2010.09.023

Field, A. (2013). Discovering Statistics Using SPSS (4th ed.). Thousand Oaks, CA: Sage.

Fleming, K. N., Newton, T. L., Fernandez-Botran, R., Miller, J. J., \& Burns, V. E. (2012). Intimate partner stalking victimization and posttraumatic stress symptoms in post-abuse women. Violence Against Women, 18, 1368-1389. doi: 10.1177/1077801212474447

Flicker, S. M., Cerulli, C., Zhao, X., Tang, W., Watts, A., Xia, Y., \& Talbot, N. L. (2011). Concomitant forms of abuse and help-seeking behavior among White, African American, and Latina women who experience intimate partner violence. Violence Against Women, 17, 1067-1085. doi: 10.1177/1077801211414846

Ford-Gilboe, M., Varcoe, C., Noh, M., Wuest, J., Hammerton, J., Alhalal, E., \& Burnett, C. (2015). Patterns and predictors of service use among women who have separated from an abusive partner. Journal of Family Violence, 30, 419-431. doi: 10.1007/s10896-015$9688-8$ 
Forjuoh, S. N., Coben, J. H., \& Gondolf, E. W. (1998). Correlates of injury to women with partners enrolled in batterer treatment programs. American Journal of Public Health, $88(11), 1705-1708$.

Goodman, L., Dutton, M. A., Vankos, N., \& Weinfurt, K. (2005). Women's resources and use of strategies as risk and protective factors for reabuse over time. Violence Against Women, 11, 311-336. doi: 10.1177/1077801204273297

Grossman, S. F., \& Lundy, M. (2007). Domestic violence across race and ethnicity: Implications for social work practice and policy. Violence Against Women, 13, 1029-1052. doi: $10.1177 / 1077801207306018$

Guskiewicz, K. M., Marshall, S. W., Bailes, J., McCrea, M., Cantu, R. C., Randolph, C., \& Jordan, B. D. (2005). Association between recurrent concussion and late-life cognitive impairment in retired professional football players. Neurosurgery, 57, 719-724. doi: 10.1227/01.Neu.0000175725.75780.Dd

Hardesty, J. L., Crossman, K. A., Haselschwerdt, M. L., Raffaelli, M., Ogolsky, B. G., \& Johnson, M. P. (2015). Toward a standard approach to operationalizing coercive control and classifying violence types. Journal of Marriage and Family, 77, 833-843. doi: 10.1111/jomf.12201

Johnson, M. P. (1995). Patriarchal terrorism and common couple violence: Two forms of violence against women. Journal of Marriage and the Family, 57(2), 283-294.

Johnson, M. P. (2006). Conflict and control - Gender symmetry and asymmetry in domestic violence. Violence against Women, 12, 1003-1018. doi: 10.1177/1077801206293328 
Johnson, M. P., \& Leone, J. M. (2005). The differential effects of intimate terrorism and situational couple violence: Findings from the National Violence Against Women Survey. Journal of Family Issues, 26, 322-349. doi: 10.1177/0192513X04270345

Johnson, M. P., Leone, J. M., \& Xu, Y. (2014). Intimate terrorism and situational couple violence in general surveys: Ex-spouses required. Violence Against Women, 20, 186-207. doi: $10.1177 / 1077801214521324$

Kelly, J. B., \& Johnson, M. P. (2008). Differentiation among types of intimate partner violence: Research update and implications for interventions. Family Court Review, 46, 476-499. doi: 10.1111/j.1744-1617.2008.00215.x

Leone, J. M., Johnson, M. P., \& Cohan, C. L. (2007). Victim help seeking: Differences between intimate terrorism and situational couple violence. Family Relations, 56(5), 427-439.

Moffitt, T. E., Caspi, A., Krueger, R. F., Magdol, L., Margolin, G., Silva, P. A., \& Sydney, R. (1997). Do partners agree about abuse in their relationship? A psychometric evaluation of interpartner agreement. Psychological Assessment, 9(1), 47-56.

Monahan, K., \& O'Leary, K. D. (1999). Head injury and battered women: An initial inquiry. Health \& Social Work, 24(4), 269-278.

Newton, T. L., Burns, V. E., Miller, J. J., \& Fernandez-Botran, G. R. (2015). Subjective sleep quality in women with divorce histories: The role of intimate partner victimization. Journal of Interpersonal Violence. Advance online publication. doi: $10.1177 / 0886260514567961$

Newton, T. L., Fernandez-Botran, R., Miller, J. J., \& Burns, V. E. (2014). Interleukin-6 and soluble interleukin-6 receptor levels in posttraumatic stress disorder: Associations with 
lifetime diagnostic status and psychological context. Biological Psychology, 99, 150-159. doi: 10.1016/j.biopsycho.2014.03.009

Newton, T. L., Fernandez-Botran, R., Miller, J. J., Lorenz, D. J., Burns, V. E., \& Fleming, K. N. (2011). Markers of inflammation in midlife women with intimate partner violence histories. Journal of Women's Health, 20, 1871-1880. doi: 10.1089/jwh.2011.2788

Pakieser, R. A., Lenaghan, P. A., \& Muelleman, R. L. (1998). Battered women: Where they go for help. Journal of Emergency Nursing, 24(1), 16-19.

Reina, A. S., Lohman, B. J., \& Maldonado, M. M. (2014). "He said they'd deport me": Factors influencing domestic violence help-seeking practices among Latina immigrants. Journal of Interpersonal Violence, 29, 593-615. doi: 10.1177/0886260513505214

Riddell, T., Ford-Gilboe, M., \& Leipert, B. (2009). Strategies used by rural women to stop, avoid, or escape from intimate partner violence. Health Care Women International, 30, 134-159. doi: 10.1080/07399330802523774

Straus, M. A., Hamby, S. L., Boney-McCoy, S., \& Sugarman, D. B. (1996). The Revised Conflict Tactics Scales (CTS2). Journal of Family Issues, 17, 283-316. doi: $10.1177 / 019521396017003001$

Tolman, R. M. (1999). The validation of the Psychological Maltreatment of Women Inventory. Violence and Victims, 14(1), 25-37.

Waldrop, A. E., \& Resick, P. A. (2004). Coping among adult female victims of domestic violence. Journal of Family Violence, 19, 291-302. doi:

10.1023/B:Jofv.0000042079.91846.68 
Table 1

Descriptive Statistics

\begin{tabular}{ll}
\hline \multicolumn{1}{c}{ Variable } & Median (IQR) or \% of Sample $(n)$ \\
\hline Age & $55.22(5.75)$ \\
Ethnicity & \\
Caucasian/White & $79.19 \%(156)$ \\
African American/Black & $18.27 \%(36)$ \\
American Indian/Alaskan Native & $0.51 \%(1)$ \\
Other & $2.03 \%(4)$
\end{tabular}

Annual income

$<\$ 20,000$

$27.32 \%(53)$

$\$ 20,000-\$ 39,999$

$31.96 \%(62)$

$\$ 40,000-\$ 59,999$

$21.13 \%(41)$

$\$ 60,000-79,999$

$9.79 \%(19)$

$\$ 80,000-\$ 99,999$

$3.61 \%(7)$

$>\$ 100,000$

$6.19 \%(12)$

Educational attainment

Partial High School Education

$3.59 \%(7)$

High School Diploma/G.E.D

$11.28 \%(22)$

Partial College/Training

$34.87 \%(68)$

College Graduate

$23.08 \%(45)$

Graduate/Professional Training

$27.18 \%(53)$

Number of times divorced/separated

One

$37.06 \%(73)$

Two

$34.52 \%(68)$

Three

$14.72 \%(29)$

Four

$13.71 \%(27)$

Years since most recent divorce

$8.87(12.55)$

Abuse Severity Indicators

$\begin{array}{lc}\text { Coercive Control } & 18.00(10.00) \\ \text { Severe Violence Exposure } & 2.00(4.00) \\ \text { General Injury } & 2.00(3.00) \\ \text { Head Injury } & 65.59 \%(61) \\ \text { Concussion } & 70.49 \%(43) \\ \text { EPO } & 45.92 \%(90)\end{array}$

Note. $\mathrm{EPO}=$ emergency protective order. $N=197$ except for severe violence exposure and EPO (196), education, years since most recent divorce (195), income (194), head injury (93), and concussion (61). 

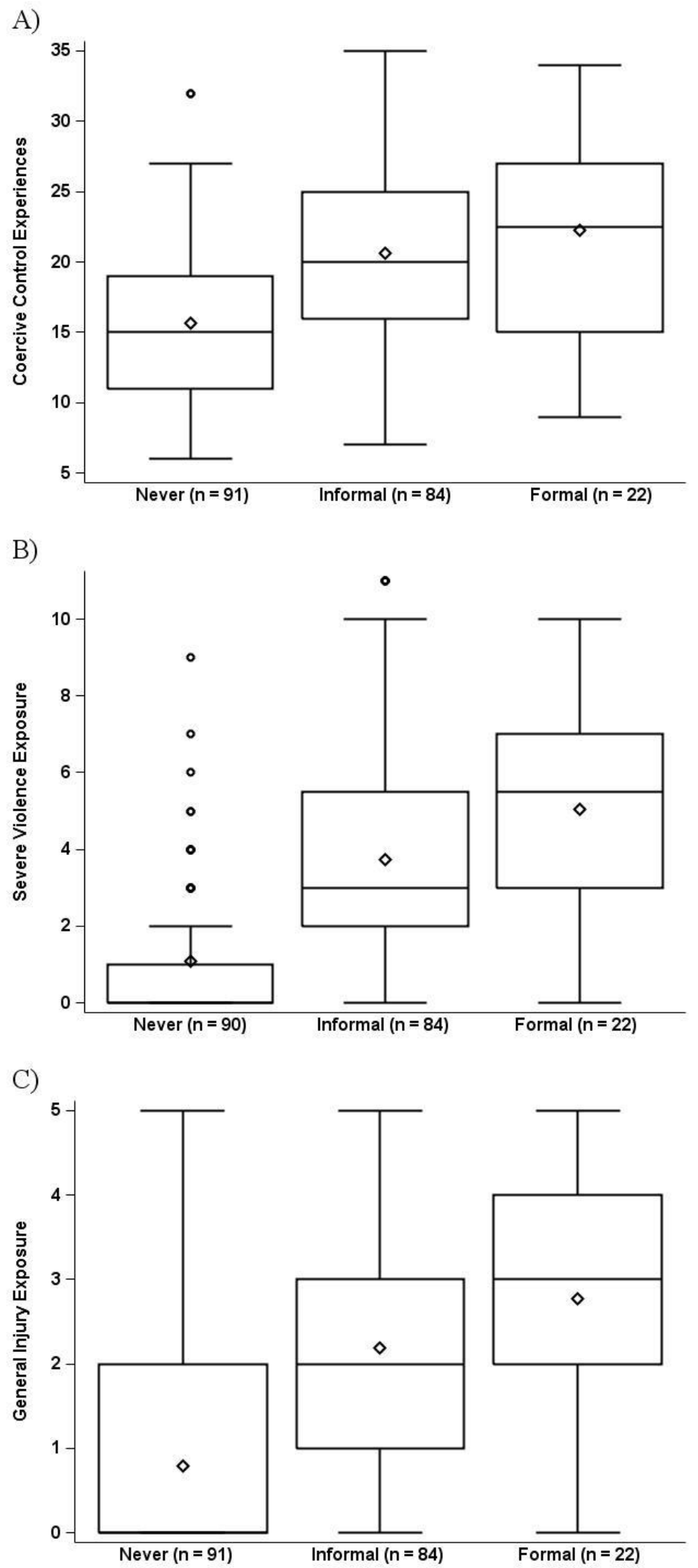

Figure 1A-C. Levels of (A) coercive control, (B) severe violence, and (C) general injury by sheltering history 
A)

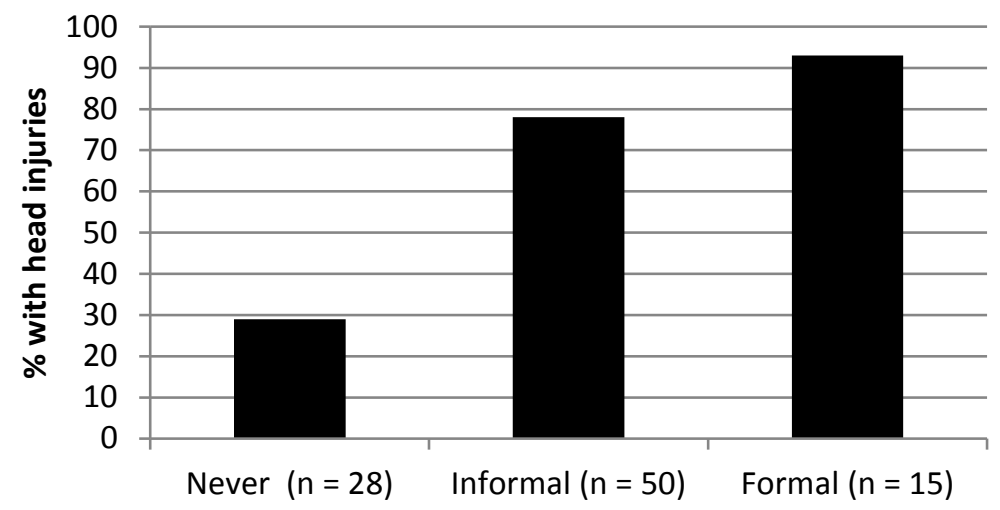

B)

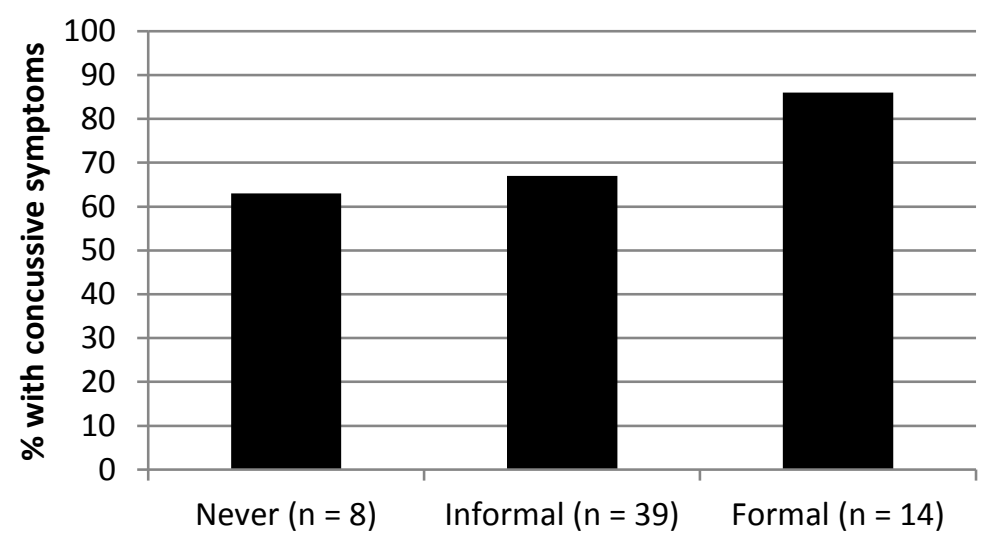

C)

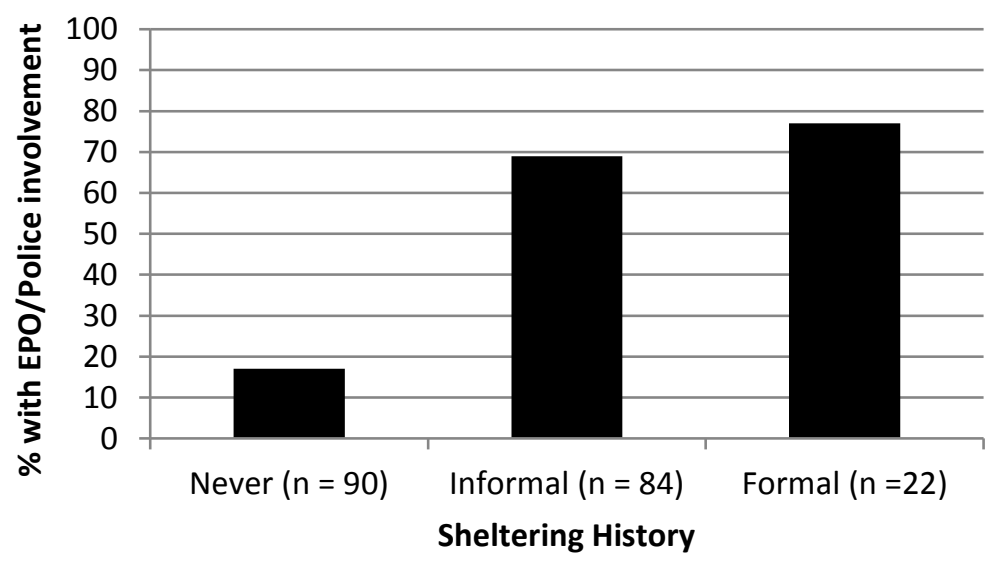

Figure 2A-C. Prevalence of (A) head injury due to violence or abuse by an intimate partner, (B) concussive symptoms, and (C) EPO/police involvement by sheltering history 


\section{BIOGRAPHICAL STATEMENTS}

Ashlee J. Warnecke, M.A., is a doctoral student at the University of Louisville. She earned a B.A. from Ohio Northern University, an M.A. from Chatham University, and an M.A. from the University of Louisville. She conducts research on the long-term functional and developmental outcomes of stress and trauma, as well as coping and resource use in those who have experienced stress and trauma.

Yvette Z. Szabo, M.A. is a doctoral student at the University of Louisville. She earned a B.S. from San José State University and an M.A. from the University of Louisville. Her interests are in factors that influence different trajectories of both mental and physical health following exposure to stressful or traumatic situations. Her particular interests are in interpersonal trauma, women's health, and both biological and psychosocial factors that might increase stress resilience.

Vicki Ellison Burns is a professor and Course Mentor for Nursing at Western Governors University, and also a Family Nurse Practitioner with specialization in vulnerable populations, women's health, psychiatric-mental health nursing, and domestic violence. She received her M.S.N. with Nurse Practitioner certification from Missouri State University, and her Ph.D. in Nursing from the University of Missouri-Columbia. Her research interests include posttraumatic stress disorder, domestic violence, adolescent pregnancy and parenting, women's health issues, and the spiritual aspects of both illness and health.

G. Rafael Fernandez-Botran is an Associate Professor in the Department of Pathology and Laboratory Medicine at the University of Louisville. He obtained a Ph.D. in Microbiology and Immunology from the University of Kansas Medical Center, and trained as a postdoctoral fellow in the Department of Microbiology at the University of Texas Southwestern Medical 
Center in Dallas. His research interests focus on cytokine biology, particularly the mechanisms that control the activity of cytokines in vivo and their role in inflammatory responses, including disease and stress-related disorders.

The late James J. Miller, Professor of Pathology and Laboratory Medicine in the University of Louisville School of Medicine, and Director of Clinical Chemistry at the University of Louisville Hospital, received his Ph.D. in Biochemistry from the University of Louisville, and completed a two-year fellowship in Clinical Chemistry at the same institution. His interests spanned markers of posttraumatic brain disorder, biomarker validation and application, mechanisms of interference, and clinical laboratory informatics.

Tamara L. Newton, Ph.D., is Associate Professor of Psychology at the University of Louisville. She earned a B.A. from the University of Michigan, and a Ph.D. from Rutgers University. She completed an internship at the Medical University of South Carolina, focusing on trauma-related disorders, and a postdoctoral fellowship in psychoneuroimmunology at the Ohio State University School of Medicine. She conducts interdisciplinary research on mechanisms of stress — cognitive, affective, and physiological — that are implicated in mental and physical health. She has special interests in mechanisms of stress recovery in women, particularly following interpersonal trauma. 